review articles useful; on the whole it is a book that should be in all institutional libraries but probably not in private collections.

The papers in this collection show the attempts in a variety of organisms to give a causal explanation of genetic polymorphisms in terms of differential rates of survival and reproduction of different genotypes. The issue, it seems to me, is in doubt. There have been great successes, as for example the cases of Müllerian and Batesian mimicry in moths and butterflies so brilliantly worked out by the Browers and Phillip Sheppard (who unaccountably is not represented by an essay). Natural selection not only operates, but works to make tasty butterflies look like nasty ones, and nasty ones to look like each other. And then there are the persistent failures, like the extraordinary diversity of human blood-group polymorphisms which show barely a trace of differential fecundity and mortality, despite an immense collection of data on the world's best studied species. Indeed, the only really convincing case of differential mortality in a blood group, that for $\mathrm{Rh}$ incompatibility, operates in the wrong direction!

To understand the bulk of the evidence about natural selection we must distinguish between what we may call "tautological" selection and "functional" selection. The difference can be illustrated by the work on industrial melanism in moths. Ford, Kettlewell, Clarke and Sheppard have demonstrated the undoubted protection that melanism offers against visual detection by predators in polluted areas (functional selection), but also that melanic genotypes in heterozygotes, or in larvae where the coloration is not at issue, simply leave more offspring (tautological selection). In functional selection the character itself is of advantage to the organism in its relation with physical or biotic factors of the environment. In tautological selection the character is accidental (or even not yet present, as in larvae) and some other physiological effect of the gene, unseen by the observer, must be postulated to account for the geographical or temporal variation. Indeed it is often possible to show that different genotypes really do leave different numbers of offspring in different environments, as for different sized animals in Cepaea, yet no "explanation" is known. But if the spots on ladybirds are black in indus trial areas and red in unpolluted areas, not because of the selective advantage of the colour itself, but because the enzyme that works better in polluted areas happens to give black pigment, then only in a formal and rather trivial sense is spot colour evolving because of natural selection. It will be a hollow triumph indeed for those who see natural selection as all powerful if it turns out that a very large proportion of morphological and behavioural evolution is nothing but the accidental concomitant of selection of polypeptides with greater heat stability. For it will destroy the chief purpose of all the studies on polymorphism described in Ecological Genetics and Evolution, which is to make such a clear case for the generality of functional selection that we will be able to trust functional explanations in general. Natural selection of the character states themselves is the essence of Darwinism. All else is molecular biology. R. C. LEWONTIN

\section{Staudinger's Memoirs}

From Organic Chemistry to Macromolecules: a Scientific Autobiography based on My Original Papers. By Hermann Staudinger. Translated from the German. Pp. xvi +303 . (Wiley Interscience: New York and London, January 1971.) £7.

Professor Hermann Staudinger will be best remembered as one of the founders of macromolecular chemistry. $\mathrm{He}$ was an outstanding organic chemist and in 1961 , at the age of 80 , he published in Germany his Arbeitserinnerungen. Now, some ten years later, we have the English translation under the very appropriate title From Organic Chemistry to Macromolecules. This book is much more than a catalogue of his scientific achievements. It vividly illustrates the breadth of vision which informed the pioneering work which was to lead to modern concepts of the mechanism of polymerization and the structure of vinyl compounds. We read in his own words how his views and concepts developed and how the macromolecular hypothesis emerged from a sea of conflicting views.

Before Staudinger embarked upon his studies of polymerization in the 1920 s he had been concerned with the typical problems of classical organic chemistry with its well-defined substances of low molecular weight which could be characterized by well-established methods. His scientific works fall naturally into the two divisions dealing with these two aspects of his research. During the period from his first research post with Vorlander at Halle in 1903 until he moved from Zurich to Freiburg in 1926 he worked on many problems of synthetic organic and natural product chemistry. His most important contributions were to the chemistry of the ketenes. This work and his excursions into synthetic drugs, insecticides, the aroma of coffee, and so on, together with many personal recollections of his teaching work, his colleagues and leading German chemists with whom he came into contact, are the subject of the first part of his book.

Staudinger did not begin his main work on the substantiation of the macromolecular theory until he left Zurich, and the decade $1920-30$ was the vital period in his fight for what was, in his own words, "a new branch of organic chemistry". In 1920 he began his studies on the structure of macromolecular compounds, in particular polyoxymethylene, polystyrene and natural rubber, and in an important paper published in that year he deplored the prevailing tendency to formulate polymeric substances as "association compounds". He proposed in this paper the chain formulae now accepted for polystyrene and polyoxymethylene. $\mathrm{He}$ also advocated the then radical point of view that natural rubber was a long chain molecular structure. In the years that followed Staudinger relentlessly championed the molecular or primary valence structure of high polymers or macromolecules as he later chose to call them. His views were not widely accepted and disputes with his critics were many and often. His battles against the opponents of his theories on the one hand, and with those who differed from him in detail rather than in principle on the other, led him to considerable experimental work in support of his views. By 1926, however, most of the principal problems were resolved and his macromolecular hypothesis received wide acceptance. The firsthand account of the whole story from Staudinger's point of view is clearly told in the annotated and edited excerpts in his book. The story as told of the development of the macromolecular hypothesis is an account of the making of chemical history and the establishment of a branch of organic chemistry which has become more important than its principal founder could have imagined. Staudinger was awarded the Nobel Prize for his work in 1953, and the text of his Nobel Lecture, which is reproduced in these memoirs, is a notable statement and a clear summary of his outstanding contribution to chemistry. All readers of this volume will be grateful to Professor and Mrs Staudinger for this historical review of the beginnings of macromolecular chemistry. C. E. H. BAWN

\section{Spectroscopic Devices}

Spectroscopy and its Instrumentation. By P. Bousquet. Translated by K. M. Greenland. Pp. viii +239 . (Adam Hilger: London, 1971.) $£ 7$.

THE French original of this book, Spectroscopie Instrumentale, which was published in 1969, was based on a course of advanced optics for students in the Faculty of Science of the Uni- 